\title{
Expression and Role of the Intermediate-Conductance Calcium-Activated Potassium Channel KCa3.1 in Glioblastoma
}

\author{
Luigi Catacuzzeno, Bernard Fioretti, and Fabio Franciolini \\ Dipartimento di Biologia Cellulare e Ambientale, Universita' di Perugia, Via Pascoli 1, I-06123 Perugia, Italy \\ Correspondence should be addressed to Luigi Catacuzzeno, luigi.catacuzzeno@unipg.it \\ and Bernard Fioretti, fiorettibernard@libero.it
}

Received 5 February 2012; Accepted 15 March 2012

Academic Editor: Laura Cerchia

Copyright (C) 2012 Luigi Catacuzzeno et al. This is an open access article distributed under the Creative Commons Attribution License, which permits unrestricted use, distribution, and reproduction in any medium, provided the original work is properly cited.

\begin{abstract}
Glioblastomas are characterized by altered expression of several ion channels that have important consequences in cell functions associated with their aggressiveness, such as cell survival, proliferation, and migration. Data on the altered expression and function of the intermediate-conductance calcium-activated $\mathrm{K}$ (KCa3.1) channels in glioblastoma cells have only recently become available. This paper aims to (i) illustrate the main structural, biophysical, pharmacological, and modulatory properties of the KCa3.1 channel, (ii) provide a detailed account of data on the expression of this channel in glioblastoma cells, as compared to normal brain tissue, and (iii) critically discuss its major functional roles. Available data suggest that KCa3.1 channels (i) are highly expressed in glioblastoma cells but only scantly in the normal brain parenchima, (ii) play an important role in the control of glioblastoma cell migration. Altogether, these data suggest KCa3.1 channels as potential candidates for a targeted therapy against this tumor.
\end{abstract}

\section{Introduction}

Glioblastomas are the most common and aggressive among primary brain tumors. In spite of the intensive basic and clinical studies, only minor successes have been witnessed over the last decades. One-third of patients keep surviving no longer than one year from diagnosis, and average life expectancy remains dismal (12-15 months), even when radical surgical resection, chemo- and radiotherapy can be applied. The major problem with glioblastomas is their highly migratory and invasive potential into the normal brain tissue that prevents complete surgical removal of tumor cells and the extreme resistance of these cells to standard treatments [1]. To worsen the outcome of the disease is the presence in the tumor mass of a recently identified subpopulation of highly tumorigenic stem-like glioblastoma cells possessing even more invasive power, chemo- and radio-resistance than nonstem tumor cells, that are also thought to be responsible for the commonly observed tumor relapses [2-4].

Glioblastomas are characterized by a large number and variety of genetic mutations that heavily disregulate the major signaling pathways controlling cell survival, proliferation, differentiation, and invasion [5]. Among the disregulated pathways found in glioblastoma cells there are those controlling the expression of ion channels, transmembrane proteins endowed with a permeation pore that allows the passage of ions. Usually ion channels are selectively permeable to one particular ion and can open and close their permeation pore in response to chemical and physical stimuli, such as neurotransmitters, modulators, and changes in the membrane potential [6]. Ion channels have been found to be involved in several cellular functions, hallmarks of cancer cell aggressiveness, such as proliferation, apoptosis, and migration. In most cases their contribution consists in regulating two important cellular parameters, the cell volume and the intracellular $\mathrm{Ca}^{2+}$ concentration $\left(\left[\mathrm{Ca}^{2+}\right]_{\mathrm{i}}\right)[7,8]$.

By allowing the movement of $\mathrm{K}$ and $\mathrm{Cl}$ ions through the plasmamembrane, and the osmotically driven water flux, ion channels critically control the changes of cell volume that are functionally relevant for glioblastoma cells. For example, a premitotic volume condensation (PVC) is required for glioblastoma cells to switch from a bipolar into a round cell 
morphology just prior cell division. Notably, this process requires the opening of $\mathrm{Cl}$-selective $\mathrm{ClC}-3$ channels, that are markedly upregulated in glioblastoma cells as compared to healthy astrocytes [9-12]. Similarly, a cell volume reduction, the so-called apoptotic volume decrease (AVD), was observed during the staurosporine- or TRAIL (TNF-alpharelated apoptosis inducing ligand)-induced apoptosis of glioblastoma cells, and also in this case it was found to be sustained by a $\mathrm{Cl}$ channel flux, being prevented by inhibitors of $\mathrm{Cl}$ channels [13]. Cell migration and invasion through the narrow extracellular spaces of the brain parenchyma also require major changes in cell volume. These processes in addition to the $\mathrm{ClC}-3$ channels discussed above require the activity of $\mathrm{Ca}^{2+}$-activated $\mathrm{K}$-selective $\mathrm{BK}$ channels, likewise markedly upregulated in glioblastoma cells as compared to healthy astrocytes [14-16].

The important role of the $\mathrm{Ca}^{2+}$ signals in the development of glioblastoma has recently been reviewed [17]. Notably, ion channels play a critical role to this regard; besides sustaining directly the $\mathrm{Ca}^{2+}$ influxes (through $\mathrm{Ca}^{2+}$ permeable channels) they can influence the entry of extracellular $\mathrm{Ca}^{2+}$ ions by modulating the membrane potential that controls the driving force for $\mathrm{Ca}^{2+}$ influx. $\mathrm{Ca}^{2+}$ influx through the TRPC family of $\mathrm{Ca}^{2+}$-permeable channels has indeed been shown to modulate glioblastoma cell cycle progression [18-20] and to induce a CaMKII-dependent activation of ClC-3 during premitotic volume condensation [12]. In addition, glioblastoma cell migration has been shown to be accompanied by intracellular $\mathrm{Ca}^{2+}$ oscillations that are instrumental to promote the kinase-dependent detachment of focal adhesions during cell rear retraction [21, 22], and these intracellular $\mathrm{Ca}^{2+}$ oscillations can be significantly affected by the membrane hyperpolarization determined by the activity of $\mathrm{K}$ channels [23].

Perhaps the best suited ion channels to play a role in tumor development are the $\mathrm{Ca}^{2+}$-activated $\mathrm{K}(\mathrm{KCa})$ channels, as they are at the cell crossroad where $\mathrm{Ca}^{2+}$ influx, membrane potential, and outward ion fluxes, all processes governed by KCa channels, integrate to modulate a large array of cellular processes [24]. KCa channels are subdivided into three major classes according to their single channel conductance: large conductance $(150-300 \mathrm{pS}) \mathrm{K}$ channels $\left(\mathrm{BK}_{\mathrm{Ca}}\right.$ or KCa1), small conductance (2-20 pS) K channels (SK or $\mathrm{KCa} 2.1, \mathrm{KCa} 2.2, \mathrm{KCa} 2.3)$, and intermediate conductance (20-60 pS) K channels ( $\mathrm{IK}_{\mathrm{Ca}}$ or KCa3.1). Each subclass has specific biophysical and pharmacological properties that allow to identify them. KCal channels, encoded by the Kcnmal gene, are broadly expressed in various tissues. They are regulated by cytoplasmic $\mathrm{Ca}^{2+}$ but also by membrane potential. In the absence of $\mathrm{Ca}^{2+}, \mathrm{KCal}$ channels can be activated only with extreme (nonphysiological) depolarizations. Elevations in cytoplasmic $\left[\mathrm{Ca}^{2+}\right]$ shift the range of activating voltages to more negative potentials. Near resting potentials, the EC50 of the KCa1 is in the micromolar range. Paxilline, iberiotoxin, and low concentrations of tetraethyl ammonium are potent and specific inhibitors of the KCal channel. The $\mathrm{KCa} 2 . \mathrm{x}$ channels are voltage independent but more sensitive to $\mathrm{Ca}^{2+}$ (EC50 in submicromolar range) due to the presence of calmodulin associated with the C-terminus that works as
$\mathrm{Ca}^{2+}$ sensor. Apamine, but not paxilline or iberiotoxin, can selectively block the KCa2.x channels. The KCa3.1 channels, like the $\mathrm{KCa} 2 . \mathrm{x}$ channels, are voltage independent but gated by intracellular $\mathrm{Ca}^{2+}$ that binds to calmodulin and opens the channel. Clotrimazole and its derivative TRAM-34 are potent inhibitors of the KCa3.1 channels, discriminating them from other KCa channels.

KCa3.1 channels are expressed in a variety of normal and tumor cells, where they participate in important cell functions such as cell cycle progression, migration, and epithelial transport, by controlling the cell volume and the driving force for $\mathrm{Ca}^{2+}$ influx [25-27]. Here we review the major progresses that have led to our present understanding of the expression and role of the KCa3.1 channels in glioblastoma.

\section{General Properties of the KCa3.1 Channel}

The KCa3.1 channel has the overall architecture of the voltage-gated $\mathrm{K}(\mathrm{Kv})$ channel superfamily, with four subunits, each containing six transmembrane domains (S1-S6) and a pore domain (P loop) located between S5 and S6. The S4 domain, which confers voltage sensitivity to the Kv channels, shows in KCa3.1 channels only two positively charged aminoacids, as compared to the 4-7 charged residues of voltage-gated $\mathrm{K}$ channels. Channel activation is, therefore, voltage independent. The KCa3.1 channel is gated instead by the binding of intracellular $\mathrm{Ca}^{2+}$ to calmodulin, a $\mathrm{Ca}^{2+}$ binding protein that is constitutively associated with the C terminus of each channel subunit [28-30]. This $\mathrm{Ca}^{2+}$ dependent gating is similar to that displayed by the $\mathrm{KCa} 2 . \mathrm{x}$ channel family but distinct from KCal channels, where the $\mathrm{Ca}^{2+}$-dependent module is intrinsic to the channel $\alpha$ subunit [24]. Patch-clamp experiments in several cell types, including glioblastoma, give IC50s for KCa3.1 channel activation by $\mathrm{Ca}^{2+}$ of 200-400 nM [31,32], consistent with those found for the cloned channel [33-35]. The high $\mathrm{Ca}^{2+}$ sensitivity of the KCa3.1 channel allows its activation by submicromolar $\mathrm{Ca}^{2+}$ levels, easily reached upon $\mathrm{Ca}^{2+}$ release from intracellular stores or influx through $\mathrm{Ca}^{2+}$ permeable channels. A fourstate gating scheme was proposed for KCa3.1 channels, with $\mathrm{Ca}^{2+}$-dependent transitions dependent on the $\left[\mathrm{Ca}^{2+}\right]_{\mathrm{i}}$ in a nonlinear manner [36]. This peculiarity, not shared by the KCa2.x channel family [37], is related to the channel behaviour at saturating $\left[\mathrm{Ca}^{2+}\right]_{i}$, as elevated divalent concentrations have been reported to block the channel $[36,38]$. The most studied KCa3.1 mRNA is the $2.1 \mathrm{~kb}$ form, but other transcripts have been reported in humans [34, 35]. Three distinct Kcnn 4 cDNAs that are designated as Kcnn4a, Kcnn4b, and Kcnn4c encoding 425, 424, and 395 aminoacid proteins, respectively, were isolated from the rat colon, and several differences in the functional expression and pharmacological properties of the different isoforms were found [39].

The KCa3.1 channels are target for several inhibitory and activatory agents (for an exhaustive review see [40]). Two structurally distinct groups of $\mathrm{KCa} 3.1$ channel blockers, peptidic and nonpeptidic, have been found which also differ for their binding site on the channel protein. Among the peptidic blockers, maurotoxin and charybdotoxin display 
the strongest potency. Maurotoxin, is a 34-aminoacid toxin cross-linked by four disulfide bridges [41]. Lys23 of the toxin binds to the pore filter of the channel from the extracellular side, and a $\pi-\pi$ interaction between tyr 32 of the toxin and a cluster of aromatic residues in the channel pore vestibule stabilizes the interaction [42]. Maurotoxin is not selective for KCa3.1 channels, being also a potent blocker of some members of $\mathrm{Kv}$ channels [41]. Charybdotoxin (ChTX), a 37-aminoacid toxin, displays a block mechanism similar to maurotoxin, and poor selectivity, blocking effectively other ion channels including KCal channels [43]. Several nonpeptidic molecules have been found to block KCa3.1 channels, such as the vasodilator cetiedil $[44,45]$, the antimycotic triarylmethane clotrimazole (CTL, [46]), and the antihypertensive L-type $\mathrm{Ca}^{2+}$ channel blocker nifedipine [47]. From chemical modification of cetiedil several more potent KCa3.1 channel blockers were obtained. The investigation of one of these compounds, the UCL 1608, suggests that they interact with a lipophilic-binding site located within the membrane [48]. Also the chemical modification of the poorly selective CTL has led to the production of several more effective KCa3.1 channel blockers, including the triarylmethanes TRAM-34 [49] and ICA-17043 [50]. TRAM-34 is so far the best probe to study the roles of KCa3.1 channels, being much more selective than CTL [49]. An excellent work has conclusively delineated the properties of the KCa3.1 channel binding site for TRAM-34 [51]. These authors found that the TRAM-34 analogue and membrane impermeant TRAM-30 blocked the channel only when applied from inside, and the interaction of TRAM-34 with the channel required the P-loop aminoacid Thy250 and the S6 segment aminoacid Val275, both likely facing a large water-filled cavity localized below the narrow selectivity filter of the channel. They thus concluded that the TRAM-34 binding site is accessible from the cytoplasmic side and lays well up inside the inner vestibule. The same work has also found that the dihydropyridines-binding site is likely different from the TRAM-34 binding site, as the same mutation does not alter the blocking action of nifedipine [51]. Starting from nifedipine as lead compound, the 4-phenil-4H-pyrans and the related cyclohexadienes were obtained [52, 53], of which cyclohexadiene 4 represents the most potent blocker of KCa3.1 channel. Particularly interesting for KCa3.1 channel targeting in glioblastomas is the analogue compound bicycle hexadiene lactone 16 , that displays a 10 -fold enrichment in brain tissue [53].

From the early discovery of 1-ethyl-2-benzimidazolinone (EBIO) as KCa3.1 channel activator [54], much effort has been devoted to increase its potency and selectivity. Potency was initially improved with the introduction of DC-EBIO [55], and more recently with NS309 [56]. Selectivity on the contrary has been more difficult to increase since these compounds activate also KCa2.x channels [40]. The mechanism of action of KCa3.1 channel activators, and the location and structure of their binding sites have been only partially clarified $[57,58]$. The potency of all KCa3.1 channel activators depends on $\mathrm{Ca}^{2+}$, as they are totally ineffective in its absence $[54,57,58]$. The origin of this $\mathrm{Ca}^{+2}$ dependence is still unclear.

\section{KCa3.1 Channel Modulation by Intracellular Messengers}

3.1. Kinase Regulation. Several studies have described a rundown of the KCa3.1 channel activity in ATP-free internal milieu that can be restored after the readdition of ATP [59], suggesting the involvement of kinases in the process. In accordance, several kinases such as PKC, PKA, and PI3Ks have been shown to regulate the KCa3.1 channels [59-61], although not through the direct phosphorylation of the channel $\alpha$ subunit $[59,61,62]$. Only the nucleotide diphosphate kinase (NDPK) has been shown to phosphorylate the KCa3.1 channel alpha subunit (at the hist358) [63], and a similar action could be exerted by adenosine monophosphate kinase (AMPK), although the aminoacid residue targeted in this case has not been identified [64]. It is possible that NDPK or AMPK represent integration points for other kinases found to modulate KCa3.1 channels, as already demonstrated for the PI3K class II [65].

3.2. Trafficking. The regulation of the pathways involved in KCa3.1 channel trafficking has been proposed as a new strategy for regulating the KCa3.1 current, since the inhibition of endocytosis by the ubiquitin-activating enzyme E1 strongly increases the number of KCa3.1 channels in the membrane [66]. In expression systems, the KCa3.1 channels at the plasma membrane have a relatively short life, being internalized within 60-90 $\mathrm{min}$ [67] and targeted for lysosomal degradation [68]. This process requires components of the ESCRT machinery and the small-molecular-weight guanine nucleotide-binding protein Rab7 [68]. Polyubiquitylation mediates the targeting of membrane-residing KCa3.1 channels to the lysosomes, while USP8 regulates the rate of KCa3.1 channel degradation by deubiquitylating KCa3.1 channels prior to lysosomal delivery [69]. This modulation could explain the increase of KCa3.1 current observed following short exposure ( $90 \mathrm{~min}$ ) of glioblastoma cells to CXCL12, since noise analysis indicates that the KCa3.1 current increase is due to an increased number of channels in the membrane (our unpublished data), while no changes in the KCa3.1 channel mRNA levels are observed [70].

3.3. Transcriptional Regulation. Two main transcription factors have been found to regulate the KCa3.1 channel expression, AP-1 and REST. AP-1 was first identified in T lymphocytes where its activity, stimulated by the ERK1/2 pathway, promotes an increase in KCa3.1 current and cell proliferation [71]. In the glioblastoma cell line GL-15 the inhibition of ERK1/2 by the MEK inhibitors PD98059 reduces the mRNA levels for the KCa3.1 channels, suggesting that the same modulation described in $\mathrm{T}$ lymphocytes is also working in glioblastoma models [32]. This modulation is relevant as the ERK1/2 pathway is deregulated in most glioblastomas, because of the several mutations accumulated during gliomagenesis [72]. The second transcription factor found to modulate the KCa3.1 channel expression is REST (Repressor Element 1-Silencing Transcription factor). The Kcnn4 gene contains two RE-1 sites whose occupancy by REST represses 
gene transcription. In vascular smooth muscle cells the downregulation of REST correlates with KCa3.1 channel upregulation and proliferation [73]. Thus, changes in glioblastoma REST levels could explain the ERK-independent Kcnn4 transcriptional downregulation we found in GL-15 glioblastoma cells with time of culture [32]. REST has in fact been shown to negatively regulate the adult CNS differentiation [74, 75], and KCa3.1 mRNA downregulation was found to be accompanied by the appearance of several differentiation markers [32].

\section{Expression of KCa3.1 Channels in Glioblastoma and Healthy Tissues}

Early evidence for the expression of KCa3.1 channels in glioma cells came from biochemical and electrophysiological studies performed about twenty years ago. In rat C6 glioma cell line it was first observed that $\mathrm{Ca}^{2+}$ ionophores induced a rubidium flux sensitive to nanomolar concentration of ChTX but not to IbTX, TEA, and apamin [76, 77]. Patch-clamp experiments in the same cell line confirmed the presence of a K-selective channel having a unitary conductance of $26 \mathrm{pS}$ in symmetrical $\mathrm{K}$ and a sensitivity to submicromolar $\left[\mathrm{Ca}^{2+}\right]_{\mathrm{i}}$ $[77,78]$. This channel could also be activated by several physiological $\mathrm{Ca}^{2+}$ agonists, such as endothelin, serotonin, histamine, and bradykinin [23, 79-84].

Subsequent work from our laboratory showed that the KCa3.1 channel was also expressed in human glioblastoma cell lines (GL-15 and U251; $[32,85])$. Coapplication of the $\mathrm{Ca}^{2+}$ ionophore ionomycin with the $\mathrm{KCa} 2 / \mathrm{KCa} 3.1$ channel activator EBIO evoked in these cell lines a sustained $\mathrm{K}$ current inhibited by ChTX, CTL, and TRAM-34 but not by the KCa2 channel blocker d-TC. Single channel recordings confirmed the presence of a unitary $\mathrm{K}$ current with biophysical and pharmacological properties congruent with those reported for the cloned human KCa3.1 channel [32$35,85]$. In accordance, the KCa3.1 channel transcripts could be amplified from both GL-15 and U251 cells [32].

Besides the U251 cell line, the KCa3.1 channel transcripts were also found by Sontheimer's group in D54-MG, another human glioblastoma cell line, as well as in a human glioblastoma biopsy [86]. These authors, however, found neither evidence for a KCa3.1 current in these tissues (probed in whole-cell configuration with a $\left[\mathrm{Ca}^{2+}\right]_{\mathrm{i}}$ of $750 \mathrm{nM}$ ), nor for the KCa3.1 channel protein (using western blot analysis and commercially anti-KCa3.1 antibody) [86].

With regard to this apparent discrepancy on the functional expression of KCa3.1 channels in human glioblastoma cells, a third group recently found a substantial level of KCa3.1 channel transcripts in U87 and U251 cell lines, as well as in a glioblastoma biopsy [87]. Moreover, they found that the same cells displayed a voltage insensitive, $\mathrm{Ca}^{2+}$-activated K-selective current blocked by CTL and TRAM-34, indicating that the KCa3.1 channel was expressed in human glioblastoma cells. The expression of the KCa3.1 channel protein in glioblastoma cells was further confirmed by the same group with western blot analysis [88]. These authors tried to explain the discrepancy of their results with those of Sontheimer's group by considering the different experimental conditions used in the whole-cell recordings and the different sensitivity of the antibodies used in the western blot analysis.

The high expression of the KCa3.1 channel in glioblastoma cells could have a major diagnostic and therapeutic relevance, provided that its presence in the brain was restricted to the transformed glial cells. Early work performed soon after the cloning of the human KCa3.1 channel showed that the KCa3.1 channel transcripts were not expressed in the human central nervous system, although they were found in many other human tissues (placenta, lung, salivary gland, colon, prostate, thymus, spleen, bone marrow, lymph nodes, lymphocytes, and in many of these tissues the functional expression of the KCa3.1 channel was confirmed by patch clamp experiments) [33-35]. This was confirmed by an RTPCR study showing that KCa3.1 channel transcripts could be found in D54-MG and U251 human glioblastoma cell lines, as well as in a human glioblastoma biopsy but not in a grade III astrocytoma nor in normal human brain and in cultured rat astrocytes [86]. All these studies strongly suggested that the KCa3.1 channel was only scantly expressed in human normal brain tissue, while being strongly upregulated in glioblastomas.

Data from nonhuman specimen appear instead less clear. Earlier electrophysiological studies focused on normal rat and mouse glial cells did not find any evidence for the expression of the KCa3.1 channel, while reporting the presence of other $\mathrm{Ca}^{2+}$-activated $\mathrm{K}$ channels such as KCal and apamin-sensitive SK channels $[87,89,90]$. The expression of KCa3.1 channels was instead reported in cultured rat microglia [91, 92], but these cells did not appear to express KCa3.1 channels in in vivo slices [93]. Currents that could be ascribed to the KCa3.1 channel were observed in rat dorsal root ganglion and autonomous neurons [94-96], and most recently in rat cerebellar Purkinje cells [97]. Immunohistochemical analysis revealed the KCa3.1 channel protein in rat ependymal cells [98]. More recent studies indicate, however, that normal mouse astrocytes express low levels of KCa3.1 channels. More specifically, one study shows that about $10 \%$ of GFAP-positive mouse astrocytes is immunoreactive to antibody against KCa3.1 channels, and this percentage increases 5-fold following spinal cord injury. This latter result is consistent with the observation that KCa3.1 channels are highly expressed in activated astrocytes [93]. A second study also reports KCa3.1 immunoreactivity in mouse astrocytes (mostly at the endfoot) and shows that the channel participates to the neurovascular coupling. The study further shows that $50 \%$ of GFAP-positive astrocytes in slice preparation expresses TRAM-34 sensitive and NS309-activated KCa3.1 currents [99]. Taken together, these data would suggest that KCa3.1 channels are present in a fraction of normal mouse astrocytes. Further dedicated experiments are needed to conclusively clarify whether human normal astrocytes express KCa3.1 channels, and whether interspecies differences exist in the expression of KCa3.1 channels in the brain.

\section{Functional Roles of KCa3.1 Channels in Glioblastoma Cells}

5.1. Cell Proliferation and Growth. KCa3.1 channel expression has been shown to be upregulated in many cancer cell 
types, and in most of them a role of this channel in promoting cell growth and cell cycle progression has been evidenced (reviewed in [25]). A similar role in glioblastoma cells is suggested by data showing that CTL inhibits the growth of glioblastoma cell lines (by inducing a cell cycle arrest at G1-S transition) and delays the development of intracranial glioblastoma tumor formation [100-102]. However, given the several unspecific effects of CTL, these data do not conclusively show whether KCa3.1 channels have a role in the growth of glioblastoma cells. A recent work aimed at specifically addressing this issue found that both CTL and the more specific CTL analog TRAM-34 inhibited the growth of U87 and U251 cells, although with IC50s much higher than those needed to inhibit channel activity. By contrast, when inhibition of KCa3.1 current (down to 20\%) was attained by RNA interference, no measurable effect was observed on cell growth [88]. Based on these observations the authors concluded that KCa3.1 channel activity is unlikely to have a major role in glioblastoma cell proliferation, and the effects of KCa3.1 channel inhibitors are most likely unspecific. It should be noticed, however, that under the assumption that the effect of KCa3.1 channel on cell growth is mediated by the channel-induced hyperpolarization (that would facilitate $\mathrm{Ca}^{2+}$ influx through the membrane), an IC50 for cell growth inhibition higher than that for channel block has to be expected, as documented for many $\mathrm{K}$ channel blockers (reviewed in [103]). A role of KCa3.1 channels in glioblastoma cells proliferation cannot thus be excluded based on the available data, and further experiments addressing this point are needed.

5.2. Cell Migration and Invasion. More conclusive data assign a role to KCa3.1 channels in glioblastoma cell migration. Cell migration plays a crucial role in the pathophysiology of glioblastomas, and several ion channels have been shown to have a major role in this process ( $c f$. Section 1). Given the abundant expression of KCa3.1 channels in glioblastoma cells and the substantial role this channel has in the migration of other cell types [27], we recently verified whether glioblastoma cells require $\mathrm{KCa} 3.1$ channel activity to move. More specifically, we asked whether physiological motogens likely surrounding glioblastoma cells in vivo use KCa3.1 channels for their promigratory activity. Among them, the chemokine CXCL12/SDF-1 appeared of interest as its receptors CXCR4 are widely expressed in glioblastoma tissue [104107], and their activation plays a key role in the migration of glioblastoma cells [108-110]. Interestingly, we found that KCa3.1 channel activity was required in the chemotactic response to SDF-1 of GL-15 and U251 cell lines, primary cultures and freshly dissociated tissue [70]. The chemotactic response, probed with standard transwell chamber, was indeed strongly attenuated both in presence of TRAM-34 and by KCa3.1 channel silencing by RNA interference. In patch-clamp experiments we found that in a fraction of GL15 cells brief applications of SDF- 1 activate KCa3.1 channels by increasing the intracellular $\left[\mathrm{Ca}^{2+}\right]_{\mathrm{i}}$. More prolonged SDF1 applications (three hours incubation) on GL-15 cells induced instead an upregulation of the maximal KCa3.1 channel conductance, suggesting a posttranslational upregulation of the channel protein.

We further found that the KCa3.1 channel activation is not a general requirement for motogen-induced migration in glioblastoma cells. KCa3.1 channel inhibitors were in fact ineffective in modulating the chemotactic response to epidermal growth factor (EGF), another physiologically relevant chemotactic inducer in glioblastoma [111]. Patch-clamp experiments on GL-15 cells showed that EGF activates a KCa3.1 current very similar to that seen in response to SDF1. Additional experiments showed that EGF, unlike SDF-1, was not able to upregulate the KCa3.1 channel functional expression following prolonged incubation, suggesting this SDF-1-induced modulation may be the relevant one for chemotaxis.

Other in vivo promigratory signals for glioblastoma cells could be present in the serum that can infiltrate into the tumor area of glioblastomas as result of the blood-brain barrier breakdown $[112,113]$. Several studies show that fetal calf serum (FCS) enhances the migration of glioblastoma cells by inducing oscillations of the $\left[\mathrm{Ca}^{2+}\right]_{\mathrm{i}}$. $\left[\mathrm{Ca}^{2+}\right]_{\mathrm{i}}$ oscillations are thought to facilitate the detachment of focal adhesions, through stimulation of focal adhesion kinase, and the retraction of the cell rear towards the direction of movement [21]. However, since the FCS-induced $\left[\mathrm{Ca}^{2+}\right]_{\mathrm{i}}$ oscillations reach peaks sufficiently high to activate $\mathrm{KCa} 3.1$ channels, we hypothesized that $\mathrm{K}$ efflux through KCa3.1 channels could serve for the volume changes needed during cell migration. We found that in about $40 \%$ of U-87 cells, acute application of $10 \%$ FCS resulted in an oscillatory activity of a Kselective, TRAM-34 sensitive current, displaying frequencies well within those observed for the FCS-induced $\left[\mathrm{Ca}^{2+}\right]_{\mathrm{i}}$ oscillations [114]. Beside inducing a cyclical activation of KCa3.1 channels, FCS also promoted the stable (nonoscillatory) activation of a Cl-selective current having biophysical and pharmacological properties resembling those found for the volume-activated $\mathrm{Cl}$ current $(\mathrm{ICl}$, swell) widely expressed in glioblastoma cells. Coherently, transwell migration assays performed in the presence of $\mathrm{KCa} 3.1$ and $\mathrm{Cl}$ channel inhibitors indicated that the activity of these two channels was needed for the promigratory activity of FCS [114]. Finally, the $\mathrm{Cl}$ channel blocker 5-nitro-2-(3-phenylpropil) benzoic acid (NPPB) has been shown to block KCa3.1 channels at concentrations often used to block $\mathrm{Cl}$ channels [85], suggesting that the particularly high efficacy of this compound on glioblastoma cell migration [115] is due to its inhibitory effects on both channel types.

5.3. Mechanistic Roles of KCa3.1 Channels in Cell Migration. As discussed in the Introduction and illustrated in Figure 1, there are two possible mechanisms through which KCa3.1 channels could subserve glioblastoma cell migration. The first mode holds that the channel is instrumental, together with the $\mathrm{Cl}$ channel and aquaporins, to the combined outward ion flux needed for cell volume decrease. At relatively low $\left[\mathrm{Ca}^{2+}\right]_{i}$, shown to correspond to the lamellipodium protrusion, the membrane conductance is dominated by the $\mathrm{ICl}$, swell, and the membrane potential is very close to the $\mathrm{Cl}$ 


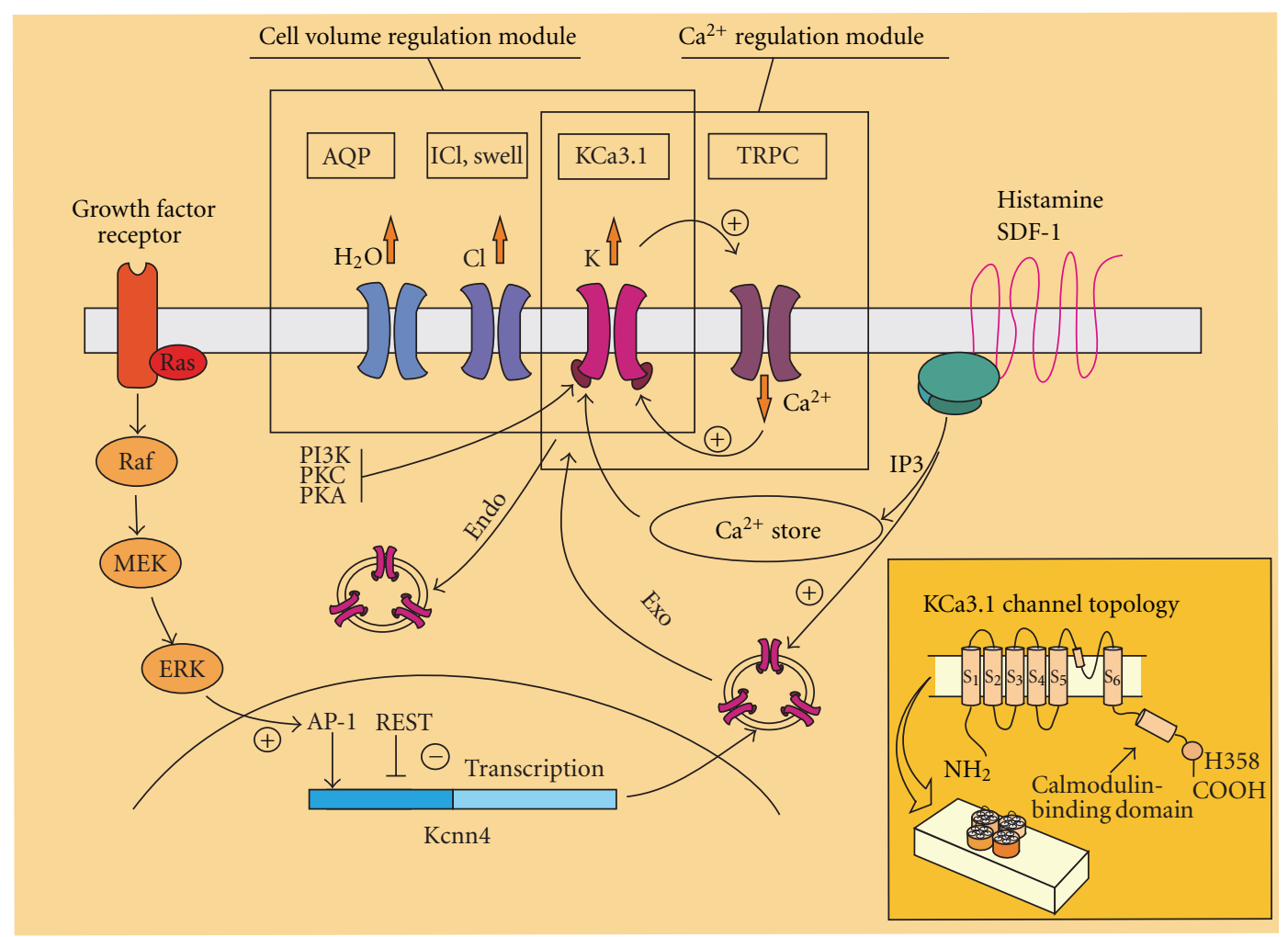

FIGURE 1: Schematic drawing illustrating the main properties and roles of the KCa3.1 channel expressed in glioblastoma cells. KCa3.1 channels can be activated by elevations of the $\left[\mathrm{Ca}^{2+}\right]_{\mathrm{i}}$ originating either from the PLC- and $\mathrm{IP}_{3}$-dependent $\mathrm{Ca}^{2+}$ release from intracellular stores triggered by G-protein-coupled receptors or from $\mathrm{Ca}^{2+}$ influx through TRPC channels. The KCa3.1 channel activity can also be regulated by several kinases, such as PI3K, PKC, and PKA. The expression of the channel is under the control of the RTK/ERK/MAPKdependent AP-1 and REST transcription factors acting on the Kcnn4 gene and further depends on the balance between endo- and exocytosis of KCa3.1 channel-containing vesicles. The drawing further highlights the two basic mechanisms sustained by the KCa3.1 channels: (i) inserted in the $\mathrm{Ca}^{2+}$ regulation module, in synergy with $\mathrm{Ca}^{2+}$ permeable channels (a TRPC in the scheme), the KCa3.1 channel amplifies the $\mathrm{Ca}^{2+}$ signals by hyperpolarizing the membrane, thus increasing the driving force for $\mathrm{Ca}^{2+}$ influx; (ii) in the cell volume regulation module, in synergy with $\mathrm{Cl}$ and aquaporin channels, the KCa3.1 channel controls the cell volume by contributing to changes in the intracellular osmolarity and water content. Inset: Top: KCa3.1 subunit topology showing the six transmembrane domain signature. The calmodulinbinding domain and the histidine phosphorilation site at the C-terminus have been indicated. Bottom: Schematic drawing showing the homotetrameric nature of functional KCa3.1 channels.

equilibrium potential (ECl). Under these conditions no transmembrane ion flux through the $\mathrm{KCa} 3.1$ and $\mathrm{Cl}$ channels is present, since there is no driving force for $\mathrm{Cl}$ ions, and KCa3.1 channels are closed. During this period the membrane transporters, usually located at the front of migrating cells [27] will bring ions and water inside the cell, thus allowing the cell volume expansion needed for cell protrusion. By contrast, the opening of KCa3.1 channels during the peaks of $\left[\mathrm{Ca}^{2+}\right]_{i}$ oscillations will move the resting membrane potential to values between $\mathrm{EK}$ and $\mathrm{ECl}$, a condition promoting both $\mathrm{K}$ and $\mathrm{Cl}$ efflux, followed by water for osmotic requirements. The resulting reduction in cell volume, accompanied by the detachment of focal adhesions located at the cell rear [21], would thus facilitate the retraction of the cell body.

Besides controlling cell volume KCa3.1 channels could promote glioblastoma cell migration through the modulation of $\left[\mathrm{Ca}^{2+}\right]_{i}$ signals. Several works have indeed shown that the activity of KCa3.1 channels facilitates the entry of $\mathrm{Ca}^{2+}$ ions from the extracellular medium by providing a counter ion to limit cell depolarization and also by hyperpolarizing the cell membrane and increasing the driving force for $\mathrm{Ca}^{2+}$ influx. This was first demonstrated in activated $\mathrm{T}$ lymphocytes [115] and subsequent works confirmed this role in other cell types expressing this channel [116-118]. In GL15 cells we found that prolonged applications of histamine induced an increase of $\left[\mathrm{Ca}^{2+}\right]_{i}$ consisting of a fast peak caused by the release of $\mathrm{Ca}^{2+}$ from the intracellular stores, followed by a sustained phase dependent on $\mathrm{Ca}^{2+}$ influx through a lanthanium-sensitive pathway. Interestingly, the activation of KCa3.1 channels significantly enhanced the sustained phase, as indicated by a reduction of the histamine-induced $\left[\mathrm{Ca}^{2+}\right]_{\mathrm{i}}$ in the presence of TRAM-34 [119]. This result strongly suggests that the activation of KCa3.1 channels could contribute to glioblastoma cell migration by modulating the shape of $\left[\mathrm{Ca}^{2+}\right]_{\mathrm{i}}$ oscillations. In accordance with this hypothesis, we recently built a theoretical model of $\left[\mathrm{Ca}^{2+}\right]_{\mathrm{i}}$ oscillations incorporating the dynamics of the membrane potential and 
found that a channel activity with the properties of KCa3.1 channels could sensibly affect IP3 driven $\left[\mathrm{Ca}^{2+}\right]_{i}$ oscillations (it increased both the amplitude and duration of each $\left[\mathrm{Ca}^{2+}\right]_{\mathrm{i}}$ spike and the oscillatory frequency) [118]. Interestingly, we found that under particular conditions the presence of KCa3.1 channel activity is necessary in order for the cell to generate $\left[\mathrm{Ca}^{2+}\right]_{\mathrm{i}}$ oscillations $[120,121]$. This last result would explain old experiments showing that the KCa3.1 channel inhibitor ChTX is able to abolish the bradykinin induced $\left[\mathrm{Ca}^{2+}\right]_{\mathrm{i}}$ oscillations in C6 glioma cells [23]. Which of the two mechanisms (cell volume regulation or control of the $\mathrm{Ca}^{2+}$ influx) is the prominent one in the control of glioblastoma cell migration by KCa3.1 channels remains to be established.

\section{Concluding Remarks}

The data presented here indicate that KCa3.1 channels play a relevant role in cell migration, a critical process in glioblastomas where the spreading and infiltration of their cells into the normal brain parenchyma represent major causes for tumor progression and recurrence following tumor surgical resection. They show in addition that KCa3.1 channels are abundantly expressed in glioblastoma cells, whereas they are only scantly present in healthy human brain tissues. These results combined would point to the KCa3.1 channels as a potential target for newer therapeutic approaches against glioblastomas. KCa3.1 channel blockers are indeed beginning to be considered in therapy, and certain results appear encouraging. First, the KCa3.1 channel blocker TRAM-34, as well as more recently developed analogs have been found to effectively penetrate into the brain and reach interesting brain concentrations after intraperitoneal injection [40, 53]. Second, a KCa3.1 channel inhibitor, Senicapoc from Icagen Inc., has already been used in phase II clinical trials for sickle cell disease and asthma and appears to be well tolerated and safe in humans [26]. Thus this compound could be a convenient starting point to develop effective drugs against glioblastoma. It would be most interesting to investigate whether KCa3.1 channels are expressed in glioblastoma stem cells, and whether they underlie, as in the ordinary glioblastoma cells, the main processes of cell growth, migration, and angiogenesis. This information would also contribute robustly to the comprehension of the glioblastoma pathophysiology. Much remains to be done instead to clarify the diagnostic and prognostic relevance associated with the expression of the KCa3.1 channel in glioblastoma cells. It would be important to this respect to verify whether the level of KCa3.1 channel expression is correlated with the grade of the tumor and the expression of other recognized tumor markers.

It would also be very important to conclusively clarify the involvement of KCa3.1 channels in the cell cycle progression of glioblastoma cells, and whether their activity is needed for other functional roles relevant to this pathology. Notably, we have preliminary evidence for an effect of TRAM-34 in the glioblastoma-induced angiogenesis, a process that allows glioblastoma cells to ensure themselves for the necessary oxygen and nutrients $[122,123]$. The relevance of this study is underpinned by the observation that antiangiogenic therapies are considered clinically very effective and promising
[124]. In the hypothesis that a role of KCa3.1 channels in the glioblastoma-induced angiogenesis will be confirmed, the use of KCa3.1 channel inhibitors may be expected particularly effective in the treatment of this pathology, given their inhibitory action on two distinct vital functions for the tumor mass, namely, cell spreading and angiogenesis.

\section{Authors' Contribution}

All authors equally contributed to this work.

\section{References}

[1] F. B. Furnari, T. Fenton, R. M. Bachoo et al., "Malignant astrocytic glioma: genetics, biology, and paths to treatment," Genes and Development, vol. 21, no. 21, pp. 2683-2710, 2007.

[2] S. Bao, Q. Wu, R. E. McLendon et al., "Glioma stem cells promote radioresistance by preferential activation of the DNA damage response," Nature, vol. 444, no. 7120, pp. 756760, 2006.

[3] G. Liu, X. Yuan, Z. Zeng et al., "Analysis of gene expression and chemoresistance of $\mathrm{CD} 133^{+}$cancer stem cells in glioblastoma," Molecular Cancer, vol. 5, article 67, 2006.

[4] A. M. Bleau, J. T. Huse, and E. C. Holland, "The ABCG2 resistance network of glioblastoma," Cell Cycle, vol. 8, no. 18, pp. 2936-2944, 2009.

[5] B. Purow and D. Schiff, "Advances in the genetics of glioblastoma: are we reaching critical mass?" Nature Reviews Neurology, vol. 5, no. 8, pp. 419-426, 2009.

[6] B. Hille, Ion Channels of Excitable Membranes, Sinauer Associates, Sunderland, Mass, USA, 3rd edition, 2001.

[7] K. Kunzelmann, "Ion channels and cancer," Journal of Membrane Biology, vol. 205, no. 3, pp. 159-173, 2005.

[8] A. Arcangeli, O. Crociani, E. Lastraioli, A. Masi, S. Pillozzi, and A. Becchetti, "Targeting ion channels in cancer: a novel frontier in antineoplastic therapy," Current Medicinal Chemistry, vol. 16, no. 1, pp. 66-93, 2009.

[9] M. L. Olsen, S. Schade, S. A. Lyons, M. D. Amaral, and H. Sontheimer, "Expression of voltage-gated chloride channels in human glioma cells," The Journal of Neuroscience, vol. 23, no. 13, pp. 5572-5582, 2003.

[10] C. W. Habela, M. L. Olsen, and H. Sontheimer, "ClC3 is a critical regulator of the cell cycle in normal and malignant glial cells," The Journal of Neuroscience, vol. 28, no. 37, pp. 9205-9217, 2008.

[11] C. W. Habela, N. J. Ernest, A. F. Swindall, and H. Sontheimer, "Chloride accumulation drives volume dynamics underlying cell proliferation and migration," Journal of Neurophysiology, vol. 101, no. 2, pp. 750-757, 2009.

[12] V. A. Cuddapah, C. W. Habela, S. Watkins et al., "Kinase activation of ClC-3 accelerates cytoplasmic condensation during mitotic cell rounding," American Journal of Physiology, vol. 302, no. 3, pp. C527-C538, 2012.

[13] N. J. Ernest, C. W. Habela, and H. Sontheimer, "Cytoplasmic condensation is both necessary and sufficient to induce apoptotic cell death," Journal of Cell Science, vol. 121, part 3, pp. 290-297, 2008.

[14] X. Liu, Y. Chang, P. H. Reinhart, and H. Sontheimer, "Cloning and characterization of glioma BK, a novel BK channel isoform highly expressed in human glioma cells," The Journal of Neuroscience, vol. 22, no. 5, pp. 1840-1849, 2002. 
[15] V. A. Cuddapah and H. Sontheimer, "Ion channels and transporters in cancer. 2. Ion channels and the control of cancer cell migration," American Journal of Physiology, vol. 301, no. 3, pp. C541-C549, 2011.

[16] H. Sontheimer, "Ion channels and amino acid transporters support the growth and invasion of primary brain tumors," Molecular Neurobiology, vol. 29, no. 1, pp. 61-71, 2004.

[17] M. F. Ritchie, Y. Zhou, and J. Soboloff, "WT1/EGR1 mediated control of STIM1 expression and function in cancer cells," Frontiers in Bioscience, vol. 16, pp. 2402-2415, 2011.

[18] X. Ding, Z. He, K. Zhou et al., "Essential role of TRPC6 channels in G2/M phase transition and development of human glioma," Journal of the National Cancer Institute, vol. 102, no. 14, pp. 1052-1068, 2010.

[19] S. Chigurupati, R. Venkataraman, D. Barrera et al., "Receptor channel TRPC6 is a key mediator of Notch-driven glioblastoma growth and invasiveness," Cancer Research, vol. 70, no. 1, pp. 418-427, 2010.

[20] V. C. Bomben and H. Sontheimer, "Disruption of transient receptor potential canonical channel 1 causes incomplete cytokinesis and slows the growth of human malignant gliomas," GLIA, vol. 58, no. 10, pp. 1145-1156, 2010.

[21] G. Giannone, P. Rondé, M. Gaire, J. Haiech, and K. Takeda, "Calcium oscillations trigger focal adhesion disassembly in human U87 astrocytoma cells," Journal of Biological Chemistry, vol. 277, no. 29, pp. 26364-26371, 2002.

[22] P. Rondé, G. Giannone, I. Gerasymova, H. Stoeckel, K. Takeda, and J. Haiech, "Mechanism of calcium oscillations in migrating human astrocytoma cells," Biochimica et Biophysica Acta, vol. 1498, no. 2-3, pp. 273-280, 2000.

[23] G. Reetz and G. Reiser, " $\left[\mathrm{Ca}^{2+}\right]_{\mathrm{i}}$ oscillations induced by bradykinin in rat glioma cells associated with $\mathrm{Ca}^{2+}$ storedependent $\mathrm{Ca}^{2+}$ influx are controlled by cell volume and by membrane potential," Cell Calcium, vol. 19, no. 2, pp. 143156, 1996.

[24] H. Berkefeld, B. Fakler, and U. Schulte, " $\mathrm{Ca}^{2+}$-activated $\mathrm{K}^{+}$ channels: from protein complexes to function," Physiological Reviews, vol. 90, no. 4, pp. 1437-1459, 2010.

[25] C. C. Chou, C. A. Lunn, and N. J. Murgolo, "KCa3.1: target and marker for cancer, autoimmune disorder and vascular inflammation?" Expert Review of Molecular Diagnostics, vol. 8, no. 2, pp. 179-187, 2008.

[26] H. Wulff and N. A. Castle, "Therapeutic potential of $\mathrm{K}_{\mathrm{Ca}} 3.1$ blockers: recent advances and promising trends," Expert Review of Clinical Pharmacology, vol. 3, no. 3, pp. 385-396, 2010.

[27] A. Schwab, V. Nechyporuk-Zloy, A. Fabian, and C. Stock, "Cells move when ions and water flow," Pflügers Archiv European Journal of Physiology, vol. 453, no. 4, pp. 421-432, 2007.

[28] X. M. Xia, B. Fakler, A. Rivard et al., "Mechanism of calcium gating in small-conductance calcium-activated potassium channels," Nature, vol. 395, no. 6701, pp. 503-507, 1998.

[29] J. E. Keen, R. Khawaled, D. L. Farrens et al., "Domains responsible for constitutive and $\mathrm{Ca}^{2+}$-dependent interactions between calmodulin and small conductance $\mathrm{Ca}^{2+}$-activated potassium channels," The Journal of Neuroscience, vol. 19, no. 20, pp. 8830-8838, 1999.

[30] W. Li, D. B. Halling, A. W. Hall, and R. W. Aldrich, "EF hands at the N-lobe of calmodulin are required for both SK channel gating and stable SK-calmodulin interaction," Journal of General Physiology, vol. 134, no. 4, pp. 281-293, 2009.

[31] P. Pedarzani and M. Stocker, "Molecular and cellular basis of small- and intermediate-conductance, calcium-activated potassium channel function in the brain," Cellular and Molecular Life Sciences, vol. 65, no. 20, pp. 3196-3217, 2008.

[32] B. Fioretti, E. Castigli, M. R. Micheli et al., "Expression and modulation of the intermediate- conductance $\mathrm{Ca}^{2+}$-activated $\mathrm{K}^{+}$channel in glioblastoma GL-15 cells," Cellular Physiology and Biochemistry, vol. 18, no. 1-3, pp. 47-56, 2006.

[33] W. J. Joiner, L. U. Y. Wang, M. D. Tang, and L. K. Kaczmarek, "hSK4, a member of a novel subfamily of calcium-activated potassium channels," Proceedings of the National Academy of Sciences of the United States of America, vol. 94, no. 20, pp. 11013-11018, 1997.

[34] N. J. Logsdon, J. Kang, J. A. Togo, E. P. Christian, and J. Aiyar, "A novel gene, hKCa4, encodes the calcium-activated potassium channel in human T lymphocytes," Journal of Biological Chemistry, vol. 272, no. 52, pp. 32723-32726, 1997.

[35] T. M. Ishii, C. Silvia, B. Hirschberg, C. T. Bond, J. P. Adelman, and J. Maylie, "A human intermediate conductance calciumactivated potassium channel," Proceedings of the National Academy of Sciences of the United States of America, vol. 94, no. 21, pp. 11651-11656, 1997.

[36] M. A. Bailey, M. Grabe, and D. C. Devor, "Characterization of the PCMBS-dependent modification of KCa3.1 channel gating," Journal of General Physiology, vol. 136, no. 4, pp. 367387, 2010.

[37] B. Hirschberg, J. Maylie, J. P. Adelman, and N. V. Marrion, "Gating of recombinant small-conductance Ca-activated $\mathrm{K}^{+}$ channels by calcium," Journal of General Physiology, vol. 111, no. 4, pp. 565-581, 1998.

[38] J. Ledoux, A. D. Bonev, and M. T. Nelson, " $\mathrm{Ca}^{2+}$-activated $\mathrm{K}^{+}$ channels in murine endothelial cells: block by intracellular calcium and magnesium," Journal of General Physiology, vol. 131, no. 2, pp. 125-135, 2008.

[39] C. Barmeyer, C. Rahner, Y. Yang, F. J. Sigworth, H. J. Binder, and V. M. Rajendran, "Cloning and identification of tissuespecific expression of KCNN4 splice variants in rat colon," American Journal of Physiology, vol. 299, no. 2, pp. C251C263, 2010.

[40] H. Wulff, A. Kolski-Andreaco, A. Sankaranarayanan, J. M. Sabatier, and V. Shakkottai, "Modulators of small- and intermediate-conductance calcium-activated potassium channels and their therapeutic indications," Current Medicinal Chemistry, vol. 14, no. 13, pp. 1437-1457, 2007.

[41] N. A. Castle, D. O. London, C. Creech, Z. Fajloun, J. W. Stocker, and J. M. Sabatier, "Maurotoxin: a potent inhibitor of intermediate conductance $\mathrm{Ca}^{2+}$-activated potassium channels," Molecular Pharmacology, vol. 63, no. 2, pp. 409-418, 2003.

[42] V. Visan, Z. Fajloun, J. M. Sabatier, and S. Grissmer, "Mapping of maurotoxin binding sites on hKv1.2, hKv1.3, and hlKCa1 channels," Molecular Pharmacology, vol. 66, no. 5, pp. 1103-1112, 2004.

[43] H. Rauer, M. D. Lanigan, M. W. Pennington et al., "Structureguided transformation of charybdotoxin yields an analog that selectively targets $\mathrm{Ca}^{2+}$-activated over voltage-gated $\mathrm{K}^{+}$ Channels," The Journal of Biological Chemistry, vol. 275, no. 2, pp. 1201-1208, 2000.

[44] L. R. Berkowitz and E. P. Orringer, "Effect of cetiecil, an in vitro antisickling agent, on erythrocyte membrane cation permeability," Journal of Clinical Investigation, vol. 68, no. 5, pp. 1215-1220, 1981.

[45] L. R. Berkowitz and E. P. Orringer, "Effects of cetiedil on monovalent cation permeability in the erythrocyte: an explanation for the efficacy of cetiedil in the treatment of sickle cell anemia," Blood Cells, vol. 8, no. 2, pp. 283-288, 1982. 
[46] J. Alvarez, M. Montero, and J. Garcia-Sancho, "High affinity inhibition of $\mathrm{Ca}^{2+}$-dependent $\mathrm{K}^{+}$channels by cytochrome P-450 inhibitors," The Journal of Biological Chemistry, vol. 267, no. 17, pp. 11789-11793, 1992.

[47] J. C. Ellory, S. J. Culliford, P. A. Smith, M. W. Wolowyk, and E. E. Knaus, "Specific inhibition of Ca-activated K channels in red cells by selected dihydropyridine derivatives," British Journal of Pharmacology, vol. 111, no. 3, pp. 903-905, 1994.

[48] C. J. Roxburgh, C. R. Ganellin, S. Athmani et al., "Synthesis and structure-activity relationships of cetiedil analogues as blockers of the $\mathrm{Ca}^{2+}$-activated $\mathrm{K}^{+}$permeability of erythrocytes," Journal of Medicinal Chemistry, vol. 44, no. 20, pp. 3244-3253, 2001.

[49] H. Wulff, M. J. Miller, W. Hänsel, S. Grissmer, M. D. Cahalan, and K. G. Chandy, "Design of a potent and selective inhibitor of the intermediate-conductance $\mathrm{Ca}^{2+}$-activated $\mathrm{K}^{+}$channel, IKCa1: a potential immunosuppressant," Proceedings of the National Academy of Sciences of the United States of America, vol. 97, no. 14, pp. 8151-8156, 2000.

[50] J. W. Stocker, L. De Franceschi, G. A. McNaughton-Smith, R. Corrocher, Y. Beuzard, and C. Brugnara, "ICA-17043, a novel Gardos channel blocker, prevents sickled red blood cell dehydration in vitro and in vivo in SAD mice," Blood, vol. 101, no. 6, pp. 2412-2418, 2003.

[51] H. Wulff, G. A. Gutman, M. D. Cahalan, and K. G. Chandy, "Delineation of the clotrimazole/TRAM-34 binding site on the intermediate conductance calcium-activated potassium channel, IKCa1," The Journal of Biological Chemistry, vol. 276, no. 34, pp. 32040-32045, 2001.

[52] K. Urbahns, E. Horváth, J. P. Stasch, and F. Mauler, "4Phenyl-4H-pyrans as $\mathrm{IK}_{\mathrm{Ca}}$ channel blockers," Bioorganic \& Medicinal Chemistry Letters, vol. 13, no. 16, pp. 2637-2639, 2003.

[53] K. Urbahns, S. Goldmann, J. Krüger et al., "IK $\mathrm{Ca}_{\mathrm{Ca}}$-channel blockers. Part 2: discovery of cyclohexadienes," Bioorganic \& Medicinal Chemistry Letters, vol. 15, no. 2, pp. 401-404, 2005.

[54] D. C. Devor, A. K. Singh, R. A. Frizzell, and R. J. Bridges, "Modulation of Cl- secretion by benzimidazolones. I. Direct activation of a $\mathrm{Ca}^{2+}$-dependent $\mathrm{K}^{+}$channel," American Journal of Physiology, vol. 271, no. 5, part 1, pp. L775-L784, 1996.

[55] S. Singh, C. A. Syme, A. K. Singh, D. C. Devor, and R. J. Bridges, "Benzimidazolone activators of chloride secretion: potential therapeutics for cystic fibrosis and chronic obstructive pulmonary disease," The Journal of Pharmacology and Experimental Therapeutics, vol. 296, no. 2, pp. 600-611, 2001.

[56] D. Strøbaek, L. Teuber, T. D. Jørgensen et al., "Activation of human IK and SK $\mathrm{Ca}^{2+}$-activated $\mathrm{K}^{+}$channels by NS309 (6,7-dichloro- $1 H$-indole-2,3-dione 3-oxime)," Biochimica et Biophysica Acta, vol. 1665, no. 1-2, pp. 1-5, 2004.

[57] C. A. Syme, A. C. Gerlach, A. K. Singh, and D. C. Devor, "Pharmacological activation of cloned intermediate- and small-conductance $\mathrm{Ca}^{2+}$-activated $\mathrm{K}^{+}$channels," American Journal of Physiology, vol. 278, no. 3, pp. C570-C581, 2000.

[58] K. A. Pedersen, R. L. Schroøder, B. Skaaning-Jensen, D. Strøbæk, S. P. Olesen, and P. Christophersen, "Activation of the human intermediate-conductance $\mathrm{Ca}^{2+}$-activated $\mathrm{K}^{+}$ channel by 1-ethyl-2-benzimidazolinone is strongly $\mathrm{Ca}^{2+}$ dependent," Biochimica et Biophysica Acta, vol. 1420, no. 1-2, pp. 231-240, 1999.

[59] A. C. Gerlach, N. N. Gangopadhyay, and D. C. Devor, "Kinase-dependent regulation of the intermediate conductance, calcium- dependent potassium channel, hIK1," The Journal of Biological Chemistry, vol. 275, no. 1, pp. 585-598, 2000 .
[60] S. Srivastava, Z. Li, L. Lin et al., "The phosphatidylinositol 3-phosphate phosphatase myotubularin- related protein 6 (MTMR6) is a negative regulator of the $\mathrm{Ca}^{2+}$-activated $\mathrm{K}^{+}$ channel $\mathrm{IK}_{\mathrm{Ca}} 3.1$," Molecular and Cellular Biology, vol. 25, no. 9, pp. 3630-3638, 2005.

[61] A. Wulf and A. Schwab, "Regulation of a calcium-sensitive $\mathrm{K}^{+}$channel (cIK1) by protein kinase C," Journal of Membrane Biology, vol. 187, no. 1, pp. 71-79, 2002.

[62] S. Srivastava, P. Choudhury, Z. Li et al., "Phosphatidylinositol 3-phosphate indirectly activates KCa3.1 via 14 amino acids in the carboxy terminus of KCa3.1," Molecular Biology of the Cell, vol. 17, no. 1, pp. 146-154, 2006.

[63] S. Srivastava, Z. Li, K. Ko et al., "Histidine phosphorylation of the potassium channel KCa3.1 by nucleoside diphosphate kinase B is required for activation of KCa3.1 and CD4 T cells," Molecular Cell, vol. 24, no. 5, pp. 665-675, 2006.

[64] H. Klein, L. Garneau, N. T. N. Trinh et al., "Inhibition of the KCa3.1 channels by AMP-activated protein kinase in human airway epithelial cells," American Journal of Physiology, vol. 296, no. 2, pp. C285-C295, 2009.

[65] S. Srivastava, L. Di, O. Zhdanova et al., "The class II phosphatidylinositol 3 kinase $\mathrm{C} 2 \beta$ is required for the activation of the $\mathrm{K}^{+}$channel KCa3.1 and CD4 T-cells," Molecular Biology of the Cell, vol. 20, no. 17, pp. 3783-3791, 2009.

[66] C. M. Balut, Y. Gao, C. Luke, and D. C. Devor, "Immunofluorescence-based assay to identify modulators of the number of plasma membrane KCa3.1 channels," Future Medicinal Chemistry, vol. 2, no. 5, pp. 707-713, 2010.

[67] Y. Gao, C. M. Balut, M. A. Bailey, G. Patino-Lopez, S. Shaw, and D. C. Devor, "Recycling of the $\mathrm{Ca}^{2+}$-activated $\mathrm{K}^{+}$channel, KCa2.3, is dependent upon RME-1, $\mathrm{Rab}_{35} / \mathrm{EPI}_{4} \mathrm{C}$, and an N-terminal domain," The Journal of Biological Chemistry, vol. 285, no. 23, pp. 17938-17953, 2010.

[68] C. M. Balut, Y. Gao, S. A. Murray, P. H. Thibodeau, and D. C. Devor, "ESCRT-dependent targeting of plasma membrane localized KCa3.1 to the lysosomes," American Journal of Physiology, vol. 299, no. 5, pp. C1015-C1027, 2010.

[69] C. M. Balut, C. M. Loch, and D. C. Devor, "Role of ubiquitylation and USP8-dependent deubiquitylation in the endocytosis and lysosomal targeting of plasma membrane KCa3.1," The FASEB Journal, vol. 25, no. 11, pp. 3938-3948, 2011.

[70] M. Sciaccaluga, B. Fioretti, L. Catacuzzeno et al., "CXCL12induced glioblastoma cell migration requires intermediate conductance $\mathrm{Ca}^{2+}$-activated $\mathrm{K}^{+}$channel activity," American Journal of Physiology, vol. 299, no. 1, pp. C175-C184, 2010.

[71] S. Ghanshani, H. Wulff, M. J. Miller et al., "Up-regulation of the IKCa1 potassium channel during T-cell activation: molecular mechanism and functional consequences," The Journal of Biological Chemistry, vol. 275, no. 47, pp. 37137-37149, 2000.

[72] E. C. Holland, "Gliomagenesis: genetic alterations and mouse models," Nature Reviews Genetics, vol. 2, no. 2, pp. 120-129, 2001.

[73] A. Cheong, A. J. Bingham, J. Li et al., "Downregulated REST transcription factor is a switch enabling critical potassium channel expression and cell proliferation," Molecular Cell, vol. 20, no. 1, pp. 45-52, 2005.

[74] Z. Gao, K. Ure, P. Ding et al., "The master negative regulator REST/NRSF controls adult neurogenesis by restraining the neurogenic program in quiescent stem cells," The Journal of Neuroscience, vol. 31, no. 26, pp. 9772-9786, 2011.

[75] N. Ballas, C. Grunseich, D. D. Lu, J. C. Speh, and G. Mandel, "REST and its corepressors mediate plasticity of neuronal 
gene chromatin throughout neurogenesis," Cell, vol. 121, no. 4, pp. 645-657, 2005.

[76] P. W. L. Tas, H. G. Kress, and K. Koschel, "Presence of a charybdotoxin sensitive $\mathrm{Ca}^{2+}$-activated $\mathrm{K}^{+}$channel in rat glioma C6 cells," Neuroscience Letters, vol. 94, no. 3, pp. 279-284, 1988.

[77] F. A. De-Allie, S. R. Bolsover, A. V. Nowicky, and P. N. Strong, "Characterization of $\mathrm{Ca}^{2+}$-activated $86 \mathrm{Rb}+$ fluxes in rat $\mathrm{C} 6$ glioma cells: a system for identifying novel IKCa-channel toxins," British Journal of Pharmacology, vol. 117, no. 3, pp. 479-487, 1996.

[78] D. Manor and N. Moran, "Modulation of small conductance calcium-activated potassium channels in C6 glioma cells," Journal of Membrane Biology, vol. 140, no. 1, pp. 69-79, 1994.

[79] S. Supattapone and C. C. Ashley, "Endothelin opens potassium channels in glial cells," European Journal of Neuroscience, vol. 3, no. 4, pp. 349-355, 1991.

[80] M. M. Gleason, E. C. Griffin, P. Nambi, and N. Aiyar, "Endothelin stimulates ${ }^{86} \mathrm{Rb}$ efflux in rat glioma C6-Bu-1 cells," Neuropeptides, vol. 20, no. 1, pp. 17-23, 1991.

[81] G. Reiser, F. Donié, and F. J. Binmöller, "Serotonin regulates cytosolic $\mathrm{Ca}^{2+}$ activity and membrane potential in a neuronal and in a glial cell line via $5-\mathrm{HT}_{3}$ and $5-\mathrm{HT}_{2}$ receptors by different mechanisms," Journal of Cell Science, vol. 93, part 3, pp. 545-555, 1989.

[82] G. Reiser, F. J. Binmöller, P. N. Strong, and B. Hamprecht, "Activation of a $\mathrm{K}^{+}$conductance by bradykinin and by inositol-1,4,5-trisphosphate in rat glioma cells: involvement of intracellular and extracellular $\mathrm{Ca}^{2+}$, Brain Research, vol. 506, no. 2, pp. 205-214, 1990.

[83] A. Ogura and T. Amano, "Serotonin-receptor coupled with membrane electrogenesis in a rat glioma clone," Brain Research, vol. 297, no. 2, pp. 387-391, 1984.

[84] T. Weiger, D. R. Stevens, L. Wunder, and H. L. Haas, "Histamine $\mathrm{H} 1$ receptors in $\mathrm{C} 6$ glial cells are coupled to calciumdependent potassium channels via release of calcium from internal stores," Naunyn-Schmiedeberg's Archives of Pharmacology, vol. 355, no. 5, pp. 559-565, 1997.

[85] B. Fioretti, E. Castigli, I. Calzuola, A. A. Harper, F. Franciolini, and L. Catacuzzeno, "NPPB block of the intermediateconductance $\mathrm{Ca}^{2+}$-activated $\mathrm{K}^{+}$channel," European Journal of Pharmacology, vol. 497, no. 1, pp. 1-6, 2004.

[86] A. K. Weaver, V. C. Bomben, and H. Sontheimer, "Expression and function of calcium-activated potassium channels in human glioma cells," GLIA, vol. 54, no. 3, pp. 223-233, 2006.

[87] L. Nowak, P. Ascher, and Y. Berwald-Netter, "Ionic channels in mouse astrocytes in culture," The Journal of Neuroscience, vol. 7, no. 1, pp. 101-109, 1987.

[88] I. F. Abdullaev, A. Rudkouskaya, A. A. Mongin, and Y. H. Kuo, "Calcium-activated potassium channels BK and IK1 are functionally expressed in human gliomas but do not regulate cell proliferation," Plos ONE, vol. 5, no. 8, Article ID e12304, 2010.

[89] H. Sontheimer, M. Perouansky, D. Hoppe, H. D. Lux, R. Grantyn, and H. Kettenmann, "Glial cells of the oligodendrocyte lineage express proton-activated $\mathrm{Na}^{+}$channels," Journal of Neuroscience Research, vol. 24, no. 4, pp. 496-500, 1989.

[90] A. Bringmann, B. Biedermann, and A. Reichenbach, "Expression of potassium channels during postnatal differentiation of rabbit Müller glial cells," European Journal of Neuroscience, vol. 11, no. 8, pp. 2883-2896, 1999.

[91] R. Khanna, L. Roy, X. Zhu, and L. C. Schlichter, "K+ channels and the microglial respiratory burst," American Journal of Physiology, vol. 280, no. 4, pp. C796-C806, 2001.
[92] V. Kaushal, P. D. Koeberle, Y. Wang, and L. C. Schlichter, "The $\mathrm{Ca}^{2+}$-activated $\mathrm{K}^{+}$channel KCNN4/KCa3.1 contributes to microglia activation and nitric oxide-dependent neurodegeneration," The Journal of Neuroscience, vol. 27, no. 1, pp. 234-244, 2007.

[93] D. Bouhy, N. Ghasemlou, S. Lively et al., "Inhibition of the $\mathrm{Ca}^{2+}$-dependent $\mathrm{K}^{+}$channel, KCNN4/KCa3.1, improves tissue protection and locomotor recovery after spinal cord injury," The Journal of Neuroscience, vol. 31, no. 45, pp. 16298-16308, 2011.

[94] F. Vogalis, J. R. Harvey, C. B. Neylon, and J. B. Furness, "Regulation of $\mathrm{K}^{+}$channels underlying the slow afterhyperpolarization in enteric afterhyperpolarization-generating myenteric neurons: role of calcium and phosphorylation," Clinical and Experimental Pharmacology and Physiology, vol. 29, no. 10, pp. 935-943, 2002.

[95] J. B. Furness, K. Kearney, H. L. Robbins et al., "Intermediate conductance potassium (IK) channels occur in human enteric neurons," Autonomic Neuroscience, vol. 112, no. 1-2, pp. 93-97, 2004.

[96] C. B. Neylon, C. J. Fowler, and J. B. Furness, "Regulation of the slow afterhyperpolarization in enteric neurons by protein kinase A," Autonomic Neuroscience, vol. 126-127, pp. 258263, 2006.

[97] J. D. Engbers, D. Anderson, H. Asmara et al., "Intermediate conductance calcium-activated potassium channels modulate summation of parallel fiber input in cerebellar Purkinje cells," Proceedings of the National Academy of Sciences ot the United States of America, vol. 109, no. 7, pp. 2601-2606, 2012.

[98] P. K. Bahia, R. Suzuki, D. C. H. Benton et al., "A functional role for small-conductance calcium-activated potassium channels in sensory pathways including nociceptive processes," The Journal of Neuroscience, vol. 25, no. 14, pp. 3489-3498, 2005.

[99] T. A. Longden, K. M. Dunn, H. J. Draheim, M. T. Nelson, A. H. Weston, and G. Edwards, "Intermediate-conductance calcium-activated potassium channels participate in neurovascular coupling," British Journal of Pharmacology, vol. 164, no. 3, pp. 922-933, 2011.

[100] H. Liu, Y. Li, and K. P. Raisch, "Clotrimazole induces a late G1 cell cycle arrest and sensitizes glioblastoma cells to radiation in vitro," Anti-Cancer Drugs, vol. 21, no. 9, pp. 841-849, 2010.

[101] M. Humayun Khalid, Y. Tokunaga, A. J. Caputy, and E. Walters, "Inhibition of tumor growth and prolonged survival of rats with intracranial gliomas following administration of clotrimazole," Journal of Neurosurgery, vol. 103, no. 1, pp. 7986, 2005.

[102] M. H. Khalid, S. Shibata, and T. Hiura, "Effects of clotrimazole on the growth, morphological characteristics, and cisplatin sensitivity of human glioblastoma cells in vitro," Journal of Neurosurgery, vol. 90, no. 5, pp. 918-927, 1999.

[103] W. F. Wonderlin and J. S. Strobl, "Potassium channels, proliferation and G1 progression," Journal of Membrane Biology, vol. 154, no. 2, pp. 91-107, 1996.

[104] A. Bajetto, F. Barbieri, A. Dorcaratto et al., "Expression of CXC chemokine receptors 1-5 and their ligands in human glioma tissues: role of CXCR4 and SDF1 in glioma cell proliferation and migration," Neurochemistry International, vol. 49, no. 5, pp. 423-432, 2006.

[105] S. Barbero, A. Bajetto, R. Bonavia et al., "Expression of the chemokine receptor CXCR4 and its ligand stromal cellderived factor 1 in human brain tumors and their involvement in glial proliferation in vitro," Annals of the New York Academy of Sciences, vol. 973, pp. 60-69, 2002. 
[106] A. Salmaggi, M. Gelati, B. Pollo et al., "CXCL12 expression is predictive of a shorter time to tumor progression in low-grade glioma: a single-institution study in 50 patients," Journal of Neuro-Oncology, vol. 74, no. 3, pp. 287-293, 2005.

[107] J. Zhang, S. Sarkar, and V. W. Yong, "The chemokine stromal cell derived factor-1 (CXCL12) promotes glioma invasiveness through MT2-matrix metalloproteinase," Carcinogenesis, vol. 26, no. 12, pp. 2069-2077, 2005.

[108] N. De La Iglesia, G. Konopka, K. L. Lim et al., "Deregulation of a STAT3-interleukin 8 signaling pathway promotes human glioblastoma cell proliferation and invasiveness," The Journal of Neuroscience, vol. 28, no. 23, pp. 5870-5878, 2008.

[109] M. Ehtesham, J. A. Winston, P. Kabos, and R. C. Thompson, "CXCR4 expression mediates glioma cell invasiveness," Oncogene, vol. 25, no. 19, pp. 2801-2806, 2006.

[110] K. Wakabayashi, F. Kambe, X. Cao et al., "Inhibitory effects of cyclosporin A on calcium mobilization-dependent interleukin-8 expression and invasive potential of human glioblastoma U251MG cells," Oncogene, vol. 23, no. 41, pp. 69246932, 2004.

[111] M. E. Berens, M. D. Rief, J. R. Shapiro et al., "Proliferation and motility responses of primary and recurrent gliomas related to changes in epidermal growth factor receptor expression," Journal of Neuro-Oncology, vol. 27, no. 1, pp. 1122, 1996.

[112] R. J. Seitz and W. Wechsler, "Immunohistochemical demonstration of serum proteins in human cerebral gliomas," Acta Neuropathologica, vol. 73, no. 2, pp. 145-152, 1987.

[113] C. V. Lund, M. T. N. Nguyen, G. C. Owens et al., "Reduced glioma infiltration in Src-deficient mice," Journal of NeuroOncology, vol. 78, no. 1, pp. 19-29, 2006.

[114] L. Catacuzzeno, F. Aiello, B. Fioretti et al., "Serum-activated $\mathrm{K}$ and $\mathrm{Cl}$ currents underlay U87-MG glioblastoma cell migration," Journal of Cellular Physiology, vol. 226, no. 7, pp. 19261933, 2011.

[115] L. Soroceanu, T. J. Manning Jr., and H. Sontheimer, "Modulation of glioma cell migration and invasion using $\mathrm{Cl}$ and $\mathrm{K}^{+}$ion channel blockers," The Journal of Neuroscience, vol. 19, no. 14, pp. 5942-5954, 1999.

[116] Y. D. Gao, P. J. Hanley, S. Rinné, M. Zuzarte, and J. Daut, "Calcium-activated $\mathrm{K}^{+}$channel $\left(\mathrm{K}_{\mathrm{Ca}} 3.1\right)$ activity during $\mathrm{Ca}^{2+}$ store depletion and store-operated $\mathrm{Ca}^{2+}$ entry in human macrophages," Cell Calcium, vol. 48, no. 1, pp. 19-27, 2010.

[117] K. Funabashi, S. Ohya, H. Yamamura et al., "Accelerated $\mathrm{Ca}^{2+}$ entry by membrane hyperpolarization due to $\mathrm{Ca}^{2+}$-activated $\mathrm{K}^{+}$channel activation in response to histamine in chondrocytes," American Journal of Physiology, vol. 298, no. 4, pp. C786-C797, 2010.

[118] E. Shumilina, R. S. Lam, F. Wölbing et al., "Blunted IgEmediated activation of mast cells in mice lacking the $\mathrm{Ca}^{2+}$ activated $\mathrm{K}^{+}$channel $\mathrm{K}_{\mathrm{Ca}} 3.1$," The Journal of Immunology, vol. 180, no. 12, pp. 8040-8047, 2008.

[119] B. Fioretti, L. Catacuzzeno, L. Sforna et al., "Histamine hyperpolarizes human glioblastoma cells by activating the intermediate-conductance $\mathrm{Ca}^{2+}$-activated $\mathrm{K}^{+}$channel," American Journal of Physiology, vol. 297, no. 1, pp. C102-C110, 2009.

[120] L. Catacuzzeno, B. Fioretti, and F. Franciolini, "A theoretical study on the role of $\mathrm{Ca}^{2+}$-activated $\mathrm{K}^{+}$channels in the regulation of hormone-induced $\mathrm{Ca}^{2+}$ oscillations and their synchronization in adjacent cells," Journal of Theoretical Biology. In press.

[121] B. Fioretti, F. Franciolini, and L. Catacuzzeno, "A model of intracellular $\mathrm{Ca}^{2+}$ oscillations based on the activity of the intermediate-conductance $\mathrm{Ca}^{2+}$-activated $\mathrm{K}^{+}$channels," Biophysical Chemistry, vol. 113, no. 1, pp. 17-23, 2005.

[122] J. Folkman, "Tumor suppression by p53 is mediated in part by the antiangiogenic activity of endostatin and tumstatin," Science's STKE, vol. 2006, no. 354, p. pe35, 2006.

[123] D. Hanahan and J. Folkman, "Patterns and emerging mechanisms of the angiogenic switch during tumorigenesis," Cell, vol. 86, no. 3, pp. 353-364, 1996.

[124] P. Kleihues, D. N. Louis, B. W. Scheithauer et al., "The WHO classification of tumors of the nervous system," Journal of Neuropathology \& Experimental Neurology, vol. 61, no. 3, pp. 215-225, 2002. 

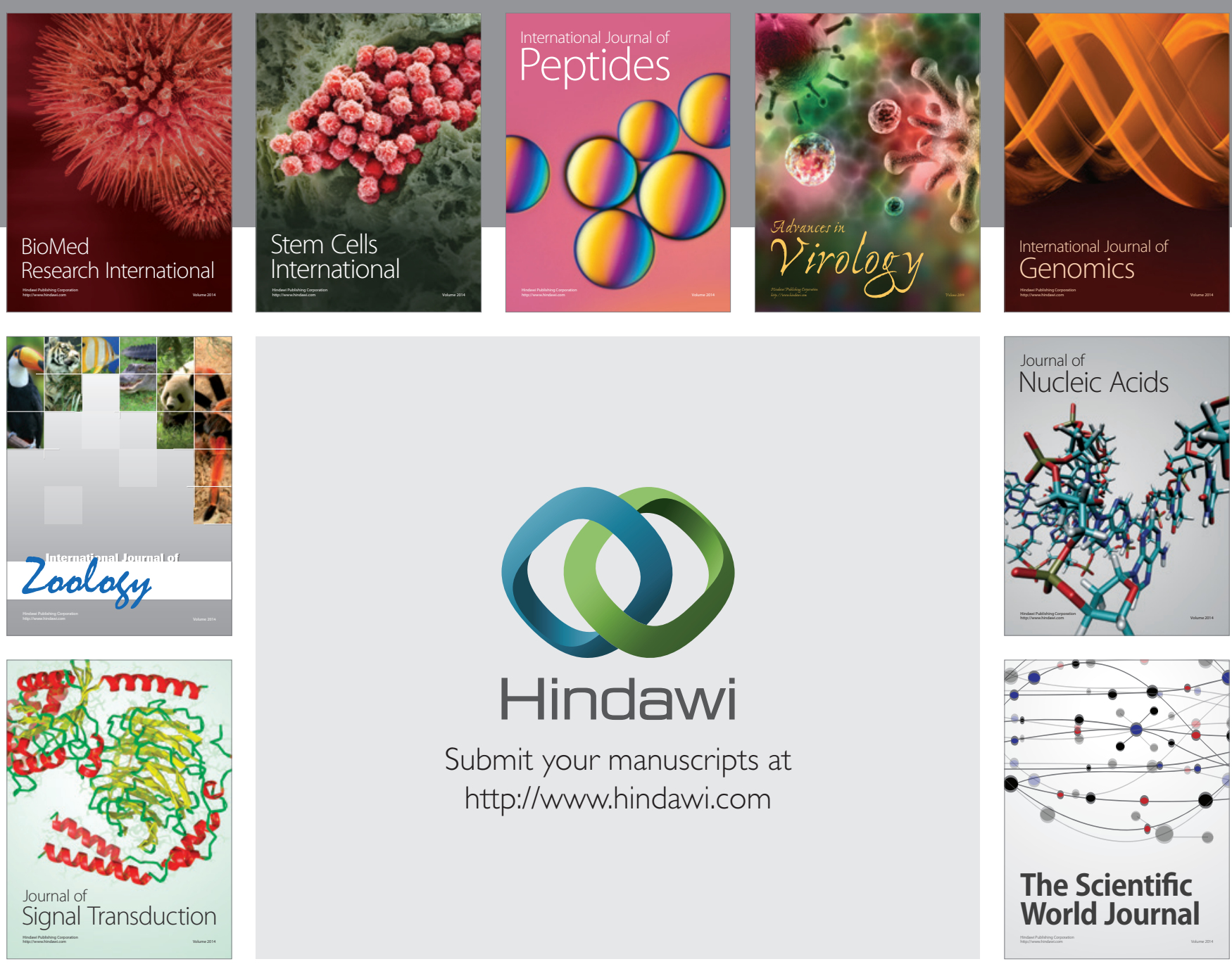

Submit your manuscripts at

http://www.hindawi.com
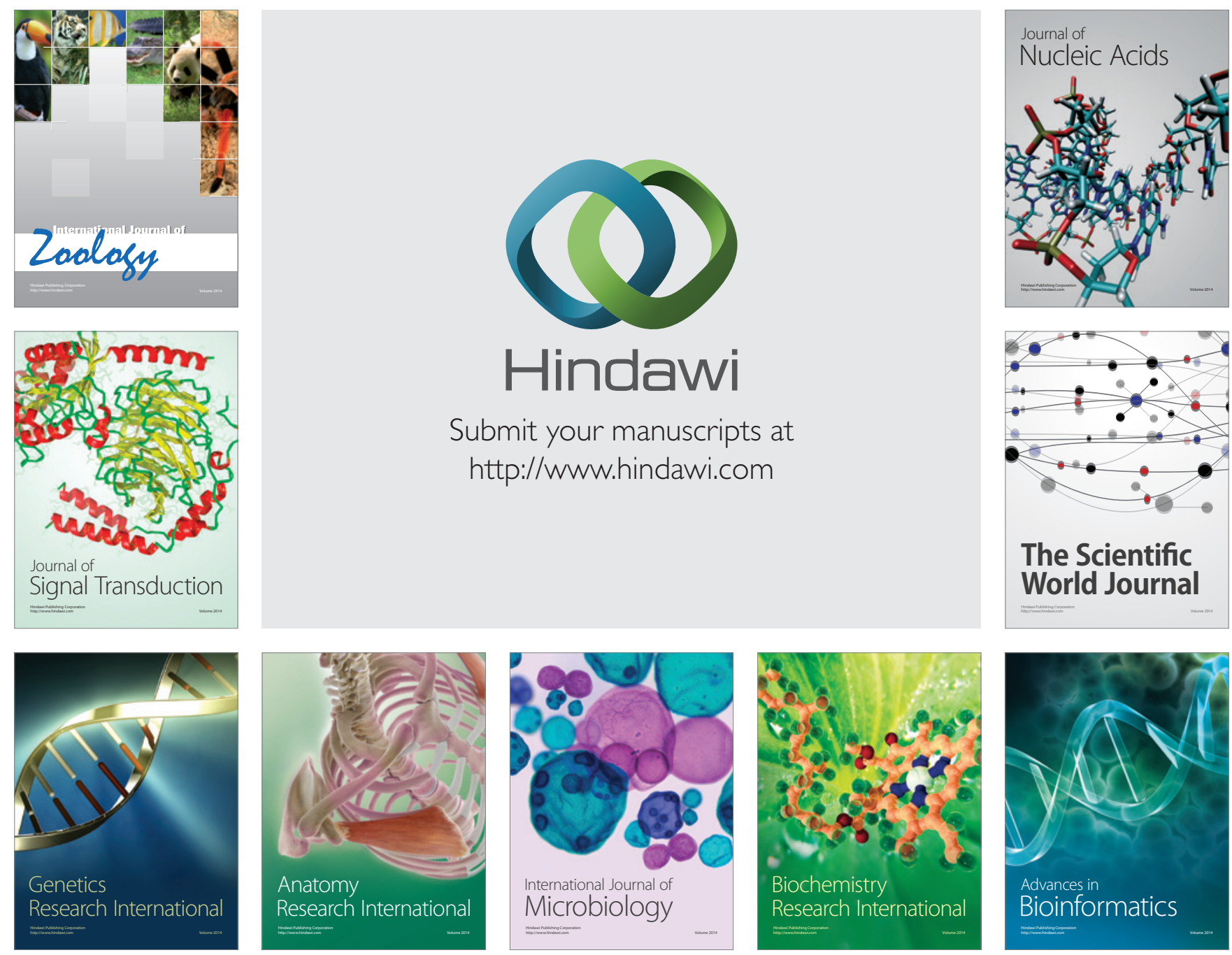

The Scientific World Journal
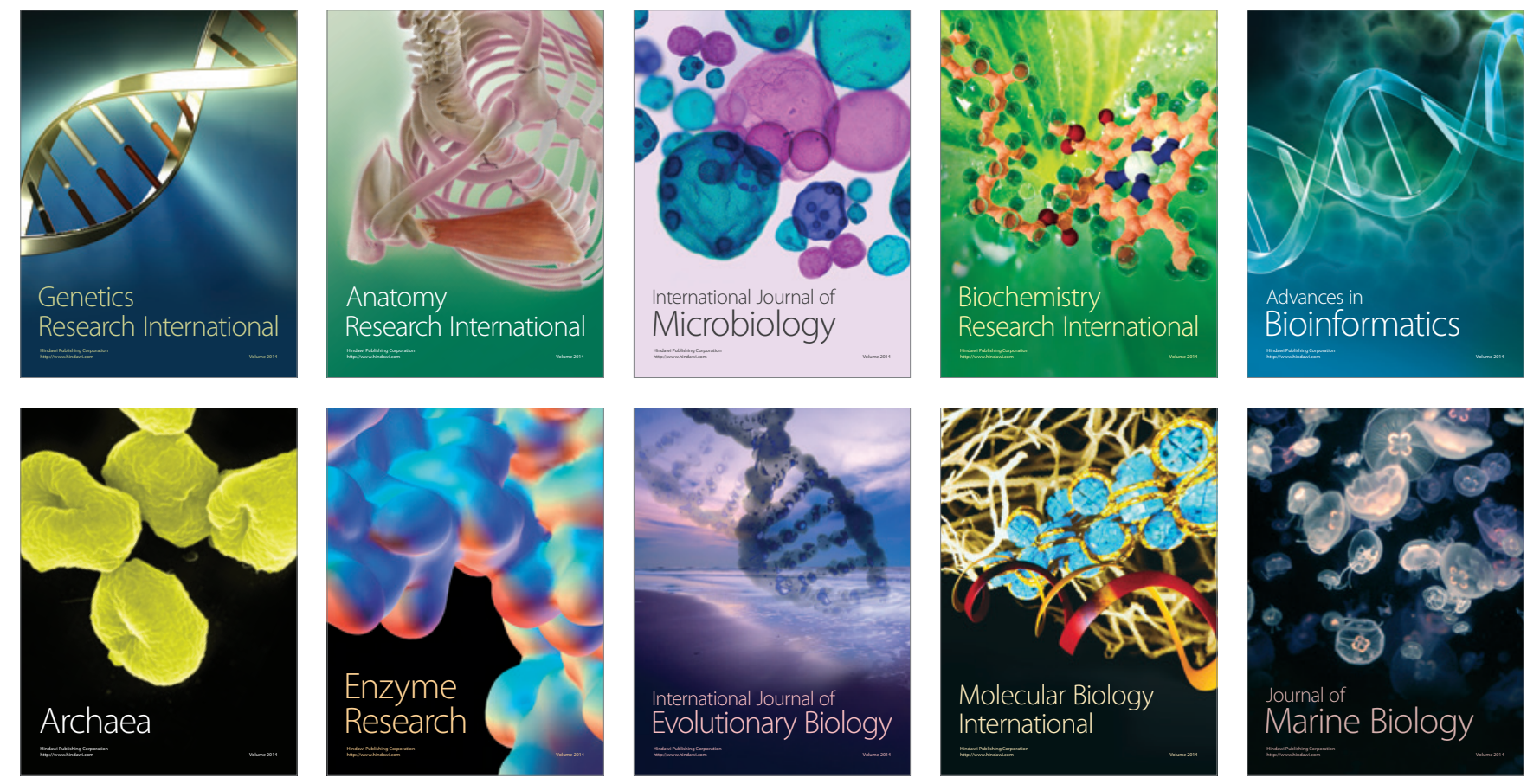